\title{
Ensaio de corrosão acelerado para avaliação do metal formador de tanques de armazenagem de biodiesel
}

\author{
Renan Francisco Bohrer Klein ${ }^{\prime}$ \\ Leonardo Felix Scheffel ${ }^{1}$ \\ Carlos Leonardo Pandolfo Carone \\ Fernando Dal Pont Morisso ${ }^{1}$ \\ Sandra Raquel Kunst ${ }^{2}$ \\ Jane Zoppas Ferreira ${ }^{2}$ \\ Cláudia Trindade Oliveira ${ }^{1 *}$ (D) \\ Luciane Taís Fuhr
}

\section{Resumo}

Com os avanços no desenvolvimento do biodiesel impulsionado pelas matrizes energéticas renováveis, o Brasil está na vanguarda da utilização de óleo vegetal e animal como combustível automotivo. A rápida evolução da produção gerou a necessidade de soluções para armazenagem de biodiesel, porém a indústria em geral utiliza tanques metálicos projetados para outros combustíveis com características físico químicas diferentes do biodiesel. A corrosão afeta a indústria de forma a gerar custos de aproximadamente $30 \%$ da instalação com posteriores substituição ou manutenções preventivas. Este trabalho buscou desenvolver uma metodologia para avaliar a corrosão do aço de tanques utilizados para armazenagem do biodiesel, devido à ausência de um ensaio especifico para análise do biodiesel como fator de corrosão. Para tanto, testes de névoa com biodiesel foram desenvolvidos em uma câmara experimental, além de ensaios de imersão e ensaio eletroquímico para comparação. Uma abordagem estatística por planejamento de experimentos foi realizada. Os resultados mostraram o caráter corrosivo do biodiesel em relação ao aço especificado, e que o enxofre presente no combustível é o fator de maior impacto na corrosão.

Palavras-chave: Avaliação da corrosão; Biodiesel; Tanques de armazenagem.

\section{Accelerated corrosion study for the metal in biodiesel storage tanks}

\begin{abstract}
With progress in biodiesel driven by renewable energy matrices, Brazil is at the forefront of using vegetable and animal oil as the automotive fuel. The dynamic production of biodiesel solutions for the production of biodiesel, since the industry in general uses metallic tanks for the development of other fuels with different physical and chemical characteristics. Industrial corrosion is a $30 \%$ industry results from installation with subsequent replacement or preventive maintenance. The work sought a methodology to evaluate the corrosion of steel from tanks used for the storage of biodiesel, due to the absence of a specific methodology for the analysis of biodiesel as a corrosion factor. Tests of cloudiness with biodiesel were developed in an experimental machine, as well as immersion tests and electrochemical tests for comparison. A statistical basis for experiment planning was performed. The results were more aggressive than the specified steel, and what is present in the fuel is the factor that has the greatest impact on corrosion.
\end{abstract}

Keywords: Evaluation of corrosion; Biodiesel; Storage tanks.

${ }^{I}$ Instituto de Ciências Exatas e Tecnológicas, ICET, Universidade Feevale, Novo Hamburgo, RS, Brasil.

${ }^{2}$ Laboratório de Corrosão, LACOR, Universidade Federal do Rio Grande do Sul, UFRGS, Porto Alegre, RS, Brasil.

*Autor correspondente: cto@feevale.br

2176-1523 (C) 2022. Klein et al. Publicado pela ABM. Este é um artigo publicado em acesso aberto (Open Access) sob a licença Creative Commons Attribution, que permite uso, distribuição e reprodução em qualquer meio, sem restrições desde que o trabalho original seja corretamente citado. 


\section{Introdução}

Com a crescente demanda por alternativas energéticas, os combustíveis renováveis apontaram um segmento de mercado promissor. Entre eles o biodiesel, por ser ambientalmente correto e biodegradável. Porém, ele possui natureza corrosiva, com características higroscópicas, além da presença de ácidos graxos em sua estrutura e resquícios do processo de transesterificação como o hidróxido de sódio, assim os tanques que armazenam biodieseis demandam cuidado em relação à manutenção. No Brasil, tanques de armazenagem verticais atmosféricos, que são os equipamentos utilizados para guardar biodiesel, devem seguir projeto, construção, utilização e manutenção pelas normas NBR 7825, NBR 7505, NBR 12235 e NBR 17505 [1].

$\mathrm{Na}$ parte interna tanques de armazenagem de biodiesel, o principal meio corrosivo é o acúmulo de água no fundo, que promove a oxidação prematura das chapas de aço do equipamento. Sendo assim, as superfícies internas apresentam maior complexidade na proteção contra corrosão [1]. Para armazenar biodiesel, a indústria não costuma utilizar pintura interna, pois o biodiesel promove a degradação acelerada do revestimento, contaminando o produto e inutilizando a proteção [2]. Além disso, as diversas impurezas encontradas no biocombustível e a presença de água, sendo um composto higroscópico [3-5] desenvolvem ambiente propicio para a evolução de micro-organismos, em grande parte bactérias [6,7]. Estas, muitas vezes, propiciam o início processo de corrosão [5], seja por produzirem substâncias corrosivas através de seu metabolismo, por criarem pilhas de aeração diferencial graças ao consumo de oxigênio, ou ainda por ação direta consumindo os elementos da liga metálica como nutriente [3]. Dentro do escopo de bactérias associadas à corrosão do Biodiesel, destacam-se os gêneros Desulfovibrio e o Desulfotomaculum, bactérias redutoras de sulfatos a sulfetos $[7,8]$. Também as bactérias oxidantes de ferro (Ferrobacillus ferrooxidans), que obtém energia diretamente da oxidação de íons ferrosos e férricos, estão relacionadas à grande numero de casos de corrosão em instalações Industriais devido a concentração de ácidos sulfúricos $[3,6,9]$. Essas são bactérias consideradas como Gram-positivas [10].

Ensaios acelerados de corrosão utilizando névoa salina são frequentemente usados para avaliar o comportamento corrosivo dos metais, mas, dado a presença de micro-organismos no biodiesel, ele não parece reproduzir adequadamente a situação no biocombustível. Assim, este estudo pretende apresentar uma proposta de ensaio acelerado adaptado usando biodiesel como eletrólito, e assim avaliar a resistência a corrosão do aço ASTM A 285 grau C dos tanques de armazenamento para biodiesel. Foram conduzidos ensaios acelerados (usando abordagem de design de experimentos - DOE) e ensaios de corrosão por imersão. As amostras de ambos foram caracterizadas por ensaios eletroquímicos e perda de massa.

\section{Metodologia}

O aço ASTM A 285 Grau C utilizado foi fornecido pela USIMINAS. As amostras $(50 \times 50 \times 7 \mathrm{~mm})$ foram decapadas quimicamente em ácido clorídrico $20 \% \mathrm{v} / \mathrm{v}$ por 2 minutos, para retirada de sujidades grosseiras. Após, seguiu-se preparação metalográfica com lixas de granulometria até 600 . Foram lavadas com água deionizada e secas com ar frio. Uma amostra foi destinada para controle, sendo guardada em dessecador para análises de comparação.

Ensaios de corrosão por imersão foram conduzidos: a) em Biodiesel tipo B100 (o que corresponde a Biodiesel puro), obtido de origem não especificada, mas que atende as especificações propostas pela ANP [11]; e b) em Biodiesel B100 com inoculação bactérias esporuladas tipo Gram-positivas, não especificadas, cultivadas a partir do próprio Biodiesel em estudo; o caldo preparado com a cepa microbiológica foi diluído em proporção de $1 \%$ de caldo em $99 \%$ de B100. Em ambos os ensaios, as amostras foram mantidas na seguinte configuração: metade da sua superfície imersa e metade exposto à atmosfera.

A avaliação dos corpos de prova (em triplicata) se deu por inspeção visual e gravimetria, após 07,15 e 30 dias [3] de imersão. Foi também realizada a medição da condutividade do meio, antes e após imersão, com condutivímetro DM-3P-PE2 marca Digimed. Os ensaios ocorreram em temperatura ambiente.

Para as análises de potencial de circuito aberto (OCP) utilizou-se como eletrólito o próprio biodiesel B100. O potencial de circuito aberto foi monitorado até estabilização do mesmo (o que ocorreu em 40 minutos) conforme norma ASTM G 5-94 [12]. O potenciostato utilizado é da marca Autolab modelo PGSTAT302, com faixa de potencial de $\pm 13 \mathrm{~V}$, com software de controle Nova, eletrodo de referência de calomelano saturado e contra eletrodo de platina. As análises foram realizadas em triplicata.

Para realização dos ensaios acelerados foi fabricado e validado um protótipo de câmara de névoa salina, seguindo especificações da ASTM B117 [13]. Um eletrólito específico foi preparado, observando a especificação do biodiesel em relação ao seu teor máximo de impurezas inorgânicas, comumente associadas a corrosão como fenômeno eletroquímico [14]. A composição do eletrólito é apresentada na Tabela 1. Os tempos de ensaio em que as amostras foram retiradas para a avaliação foram 2, 4, 6, 10, 15 e 24 horas. Foram colocadas 12 amostras na câmara, e a cada tempo de ensaio duas delas eram retiradas.

Tanto para os ensaios de corrosão por imersão quanto acelerados foi analisada a perda de massa, utilizando procedimento conforme norma ASTM G31/72 [15]. A taxa de corrosão também foi determinada segundo a referida norma. A massa das amostras foi registrada antes e após cada ensaio. Os resultados obtidos são apresentados em perda de massa por área (g.cm²).

Para uma avaliação estatística, foi realizado um Ensaio adaptado seletivo de corrosão acelerada, adotando 
o planejamento de experimento (Design of experiment $D O E$ ). Esse processo visa evidenciar qual composto presente no Biodiesel é o principal agente de corrosão dentro dele. Para tal, um ensaio com 3 amostras cada foi realizado, com ciclo exposição de 12 horas, para cada uma das soluções de eletrólito de biodiesel B100 mostradas na Tabela 2. A ordem de ensaio foi realizada de forma randômica pelo software Minitab 17; o software também foi utilizado para tratar os dados estatísticos.

Tabela 1. Composição da solução da névoa para ensaio com biodiesel

\begin{tabular}{cc}
\hline Composição & Teor \\
\hline Sulfeto de Sódio & $3 \%$ \\
$\mathrm{NaOH}$ & $1 \%$ \\
$\mathrm{KOH}$ & $1 \%$ \\
$\mathrm{CaCl}$ & $1 \%$ \\
Biodiesel & $84 \%$ \\
Metanol & $3 \%$ \\
Oxido de Fósforo & $1 \%$ \\
\hline
\end{tabular}

Tabela 2. Concentração das variáveis sobre os ensaios DOE (concentração dos componentes dissolvidos em biodiesel B100)

\begin{tabular}{|c|c|c|c|c|}
\hline Ensaio & $\mathrm{Na}_{2} \mathrm{~S}(\%)$ & $\mathrm{NaOH}(\%)$ & $\mathrm{CaCl}_{2}(\%)$ & Bactéria (\%) \\
\hline $1^{\circ}$ & 0 & 0 & 10 & 10 \\
\hline $2^{\circ}$ & 10 & 10 & 10 & 0 \\
\hline $3^{\circ}$ & 0 & 10 & 10 & 0 \\
\hline $4^{\circ}$ & 0 & 10 & 0 & 0 \\
\hline $5^{\circ}$ & 10 & 10 & 0 & 0 \\
\hline $6^{\circ}$ & 0 & 0 & 0 & 10 \\
\hline $7^{\circ}$ & 10 & 0 & 10 & 0 \\
\hline $8^{\circ}$ & 10 & 0 & 0 & 0 \\
\hline $9^{\circ}$ & 0 & 0 & 0 & 0 \\
\hline $10^{\circ}$ & 10 & 0 & 0 & 10 \\
\hline $11^{\circ}$ & 10 & 10 & 0 & 10 \\
\hline $12^{\circ}$ & 0 & 0 & 10 & 0 \\
\hline $13^{\circ}$ & 10 & 0 & 10 & 10 \\
\hline $14^{\mathrm{o}}$ & 0 & 10 & 10 & 10 \\
\hline $15^{\circ}$ & 0 & 10 & 0 & 10 \\
\hline $16^{\circ}$ & 10 & 10 & 10 & 10 \\
\hline
\end{tabular}

\section{Resultados e discussão}

\subsection{Ensaios de imersão}

$\mathrm{Na}$ análise visual, as amostras imersas em B100 puro não apresentaram variação em relação a amostra de controle, porém as amostras imersas em B100 com microrganismo inoculado apresentaram uma coloração levemente amarelada. A Figura 1 mostra a variação da perda de massa e da condutividade durante os ensaios de imersão.

Segundo Silva et al. [16] o metal quando é oxidado libera íons na solução que o cerca, sendo que a maior quantidade de íons metálicos liberados altera a condutividade da solução. Como os combustíveis apresentam baixa tendência de dissociação, o acréscimo de condutividade nas amostras deste estudo provavelmente foi devido à liberação de íons da chapa metálica, já que mesmo sem corrosão aparente as chapas perderam massa. Outro fator para aumento da condutividade segundo Sørensen et al. [17] é o processo de auto-oxidação do biodiesel. Porém, ao analisar a condutividade de uma amostra de biodiesel exposta as mesmas condições sem contato com metal após 90 dias, apresentou condutividade abaixo de todas análises ( $97 \mathrm{pS} / \mathrm{m})$, assim supôs-se que não ocorreu o processo de oxidação do biodiesel. Contudo, a perda de massa nas amostras leva crer que realmente o acréscimo da condutividade está associado à presença de íons metálicos oriundos do processo corrosivo. A perda de massa nas amostras imersas a B100 com micro-organismos inoculado foi maior que a apresentada pelo ensaio de imersão com biodiesel. Isso confirma o exposto por Videla [3], que a formação de biofilme por micro-organismos acelera as taxas de corrosão, embora não influam diretamente na natureza do processo corrosivo.

\subsection{Potencial de circuito aberto}

O potencial de circuito aberto (OCP) é definido como o potencial assumido pelo metal quando imposto um meio corrosivo, e o ensaio foi realizado para comprovar a natureza

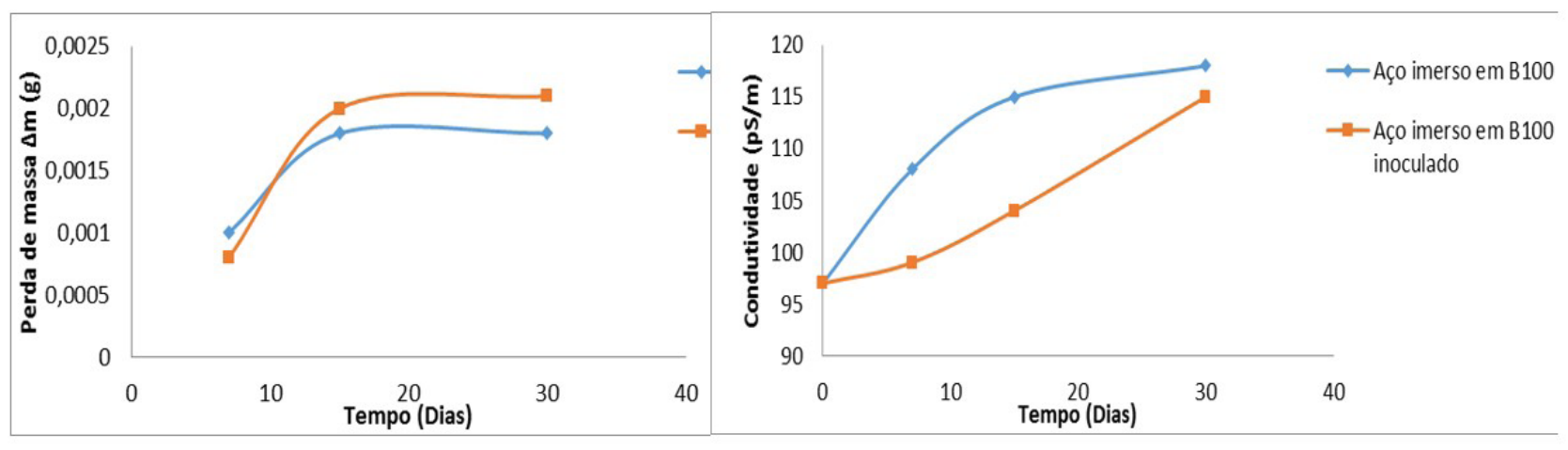

Figura 1. Avaliação da a) perda de massa e b) condutividade nos ensaios de imersão em Biodiesel B100 e em Biodiesel B100 com micro-organismos inoculados. 
oxidante do biodiesel. A Figura 2 mostra o comportamento do potencial de circuito aberto obtido. O potencial apresentou variações durante o ensaio, podendo ser interferência devido a contaminantes na placa de aço, ou na ponte salina utilizada para comunicar a tensão com o eletrodo de referência. Porém nenhuma leitura ficou abaixo de $0 \mathrm{~V}$, e portanto, segundo Skerry et al. [18], quando o potencial imposto pelo meio em análise é positivo em relação ao potencial de corrosão o metal tende à corrosão, e quando o potencial apresentando for negativo o meio está impondo a condição de proteção para o metal. Ainda assim, sugere-se que novos ensaios sejam conduzidos para melhor avaliar este comportamento.

Contudo, mesmo que preliminar, o ensaio permite avaliar que o biodiesel apresenta as características corrosivas previamente encontradas nas análises de corrosão por imersão.

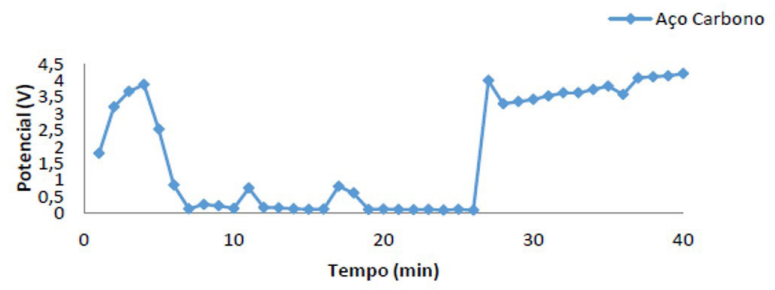

Figura 2. Transiente de potencial do aço em relação ao biodiesel.

Tabela 3. Variação de massa e taxa de corrosão nos ensaios acelerados

\begin{tabular}{ccc}
\hline $\begin{array}{c}\text { Tempo de ensaio } \\
\text { (Horas) }\end{array}$ & $\begin{array}{c}\text { Perda de massa } \\
\boldsymbol{\Delta} \mathbf{m}(\mathbf{g})\end{array}$ & $\begin{array}{c}\text { Taxa de corrosão } \\
\text { (mpy) }\end{array}$ \\
\hline 2 & 0,0045 & 39,50 \\
4 & 0,0098 & 43,01 \\
6 & 0,0151 & 44,18 \\
10 & 0,0250 & 43,89 \\
15 & 0,0371 & 43,42 \\
24 & 0,0612 & 44,77 \\
\hline
\end{tabular}

Os potenciais analisados apresentaram dois patamares estáveis de leitura entre $0,2 \mathrm{~V}$ e $0,5 \mathrm{~V}$ além de $3,0 \mathrm{~V}$ a $3,5 \mathrm{~V}$, ambos indicando a tendência do aço a oxidar no meio imposto.

\subsection{Ensaio adaptado de corrosão acelerada}

A análise visual das amostras submetidas a ensaio adaptado de corrosão acelerada mostraram corrosão tipo filiforme, por pite e generalizada, mais acentuada conforme maior o tempo de exposição no ensaio. Este resultado já era esperado. A Tabela 3 mostra o comportamento das amostras submetidas a ensaio adaptado de corrosão acelerada quanto à perda de massa e taxa de corrosão.

A taxa de corrosão (Tabela 3 ) se mostrou constante durante todas as analises, com média de 43,129 mpy $( \pm 1,98)$. A repetibilidade dos valores mostra que o conjunto manteve os padrões durante todas analises, ou seja, manteve a condição de corrosivas a taxa constante. O resultado obtido é semelhante ao encontrado por Matos [19], que obteve taxa de corrosão do aço de 39,9812 mpy em biodiesel, porém a partir de dados eletroquímicos utilizando a equação de Tafel. Assim, demonstra-se a viabilidade da metodologia proposta obter resultados experimentais próximos ao da literatura, comprovando que o biodiesel apresenta potencial de corrosão superior ao do diesel.

\subsection{Ensaio adaptado seletivo de corrosão acelerada}

A Tabela 4 apresenta o comparativo de perda de massa em percentual, buscando demonstrar qual solução apresentou maior impacto na perda de massa no sistema, consequentemente causando maior corrosão.

$\mathrm{Na}$ Tabela 4, as maiores perdas de massa foram nas soluções com misturas envolvendo o sulfeto de sódio e o cloreto de cálcio. Numa análise preliminar, a mistura de compostos poderia ser apontada como o fator predominante para a

Tabela 4. Comparação em percentual da perda de massa para os ensaios seletivos

\begin{tabular}{|c|c|c|c|c|c|c|}
\hline Ensaio & $\mathrm{Na}_{2} \mathrm{~S}(\%)$ & $\mathrm{NaOH}(\%)$ & $\mathrm{CaCl}(\%)$ & Bactéria (\%) & $\begin{array}{l}\text { Perda de massa } \\
\text { (g) }\end{array}$ & $\begin{array}{c}\text { Perda de massa } \\
(\%)\end{array}$ \\
\hline $1^{\circ}$ & 0 & 0 & 10 & 10 & 0,0091 & $6 \%$ \\
\hline $2^{o}$ & 10 & 10 & 10 & 0 & 0,0201 & $12 \%$ \\
\hline $3^{\circ}$ & 0 & 10 & 10 & 0 & 0,0101 & $6 \%$ \\
\hline $4^{\circ}$ & 0 & 10 & 0 & 0 & 0,002 & $1 \%$ \\
\hline $5^{\circ}$ & 10 & 10 & 0 & 0 & 0,0106 & $6 \%$ \\
\hline $6^{\circ}$ & 0 & 0 & 0 & 10 & 0,0003 & $0 \%$ \\
\hline $7^{\circ}$ & 10 & 0 & 10 & 0 & 0,0189 & $11 \%$ \\
\hline $8^{\circ}$ & 10 & 0 & 0 & 0 & 0,0099 & $6 \%$ \\
\hline $9^{\circ}$ & 0 & 0 & 0 & 0 & 0 & $0 \%$ \\
\hline $10^{\circ}$ & 10 & 0 & 0 & 10 & 0,0102 & $6 \%$ \\
\hline $11^{\circ}$ & 10 & 10 & 0 & 10 & 0,0107 & $6 \%$ \\
\hline $12^{\circ}$ & 0 & 0 & 10 & 0 & 0,0092 & $6 \%$ \\
\hline $13^{\circ}$ & 10 & 0 & 10 & 10 & 0,0202 & $12 \%$ \\
\hline $14^{\circ}$ & 0 & 10 & 10 & 10 & 0,0104 & $6 \%$ \\
\hline $15^{\circ}$ & 0 & 10 & 0 & 10 & 0,0021 & $1 \%$ \\
\hline $16^{\circ}$ & 10 & 10 & 10 & 10 & 0,0215 & $13 \%$ \\
\hline
\end{tabular}


perda de massa, numa ação conjunta. Mas o planejamento de experimento leva em consideração a interação de um único fator dentro dos demais e suas interações, destacando o sulfeto de sódio em todas as amostras com perdas de massa maiores, junto ao cloreto, demonstrando o verdadeiro fator de entrada que afeta de forma mais significativa o sistema.

A Figura 3 apresenta a influência direta de cada agente utilizado durante os ensaios, as inclinações das retas indicam sua real interação com o sistema, quanto maior for a inclinação, maior seu impacto corrosivo, o eixo $\mathrm{x}$ indica a variação de concentração e o seu impacto. Isso facilita o entendimento da interação dos componentes no processo corrosivo: quanto mais inclinada a curva, maior a influência na corrosão. Com maior inclinação, a presença de sulfato de sódio e responsável pela a formação de corrosão, enquanto que a presença de bactérias no sistema não teve influência tão significativa, mantendo sua inclinação praticamente muito baixa. Isso indica que sua presença não afetou o sistema (associado ao tempo necessário para formação do biofilme) de forma significativa, o que pode ter ocorrido pelo tempo utilizado nos ensaios, não suficiente para a formação de filmes biológicos, como já evidenciado pelos ensaios de imersão. O cloreto de cálcio apresentou inclinação um pouco mais acentuada do que o hidróxido de sódio, assim o hidróxido representa um menor poder de corrosão dentro do sistema em comparação com o cloreto.

A Figura 4 demonstra as interações diretas entre os fatores de entrada do sistema. Nela, o eixo y é representado pelo fator em análise e o eixo x o fator de comparação e influência. A linha tracejada representa o comportamento do fator em análise para concentração de $10 \%$, enquanto a linha continua representa a interação quando sua concentração é 0 . Quanto maior o ângulo de inclinação dessas retas, mais o fator de entrada afeta a amostra, gerando corrosão. Outra informação pode ser obtida observando as linhas do gráfico: quando o ângulo das duas retas do gráfico é o mesmo, a interação entre os fatores é baixa; porém, quando ocorre a variação do ângulo entre as retas, uma variável influi no resultado sobre a outra.

O hidróxido de sódio, sozinho, praticamente não apresentou caráter corrosivo (Figura 3), porém quando a solução tem $\mathrm{NaOH}$ e o sulfeto de sódio o poder de oxidação é maior, como pode ser visto na inclinação da reta. Segundo Appleman [20] a liberação do íon hidróxido na solução altera o pH e caracteriza uma situação favorável a corrosão, visto que possui mais oxigênio livre para as reações acontecerem. Essa situação da solução favorece o ataque dos demais agentes corrosivos em análise, neste caso o enxofre liberado pelo sulfeto de sódio.

O comparativo entre o sulfeto de sódio e o cloreto de cálcio na Figura 4 apresenta ambas as retas com a mesma inclinação; isso indica que a presença de cloreto no sistema em associação com o sulfeto de sódio não interfere no processo corrosivo, mesmo que o fator de corrosão seja maior quando os dois produtos estão juntos. Isso se deve a soma de suas contribuições, mas a presença de ambos não

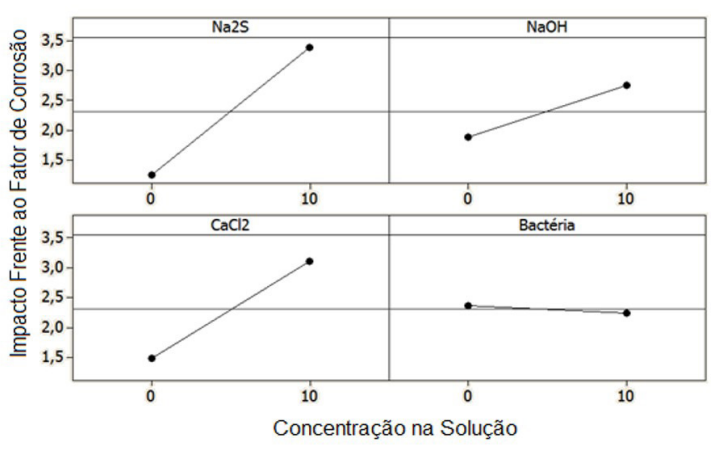

Figura 3. Representação da influência por agente em ensaio seletivo.

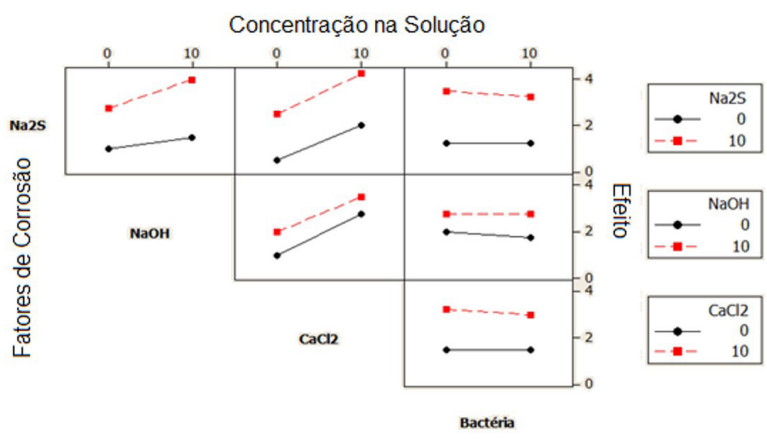

Figura 4. Interação gráfica dos resultados pelo método seletivo.

afeta a forma como irá se proceder à corrosão, mantendo os mesmos níveis de agressividade.

Como já era esperado em decorrência dos ensaios de imersão, a influência das bactérias dentro do sistema em comparação com qualquer fator de corrosão pode ser considerado nulo [21]. Pequenas variações podem ocorrer por variáveis da análise, já que as inclinações das retas de comparação (Figura 4) são praticamente nulas; isso pode estar associado ao curto espaço de tempo utilizado para análise frente ao tempo demandado para a formação do biofilme. Analisando-se a interação do cloreto com hidróxido de sódio, ambas as retas apresentam a mesma inclinação. Assim, a presença de cloreto com o NaOH não demonstrou influência, mesmo a soma dos produtos apresentando maior grau de corrosão. Este se deu pela sobreposição da ação de ambos, mas sem influência de um sobre o outro, não alterando a velocidade de corrosão.

Assim, a partir dos dados obtidos em ensaio, foi possível criar um gráfico de áreas para mostrar uma previsão da interação entre os compostos utilizados, aos pares. Nesse tipo de análise, o eixo y representa a quantidade percentual dentro da solução de elemento $\mathrm{A}$, e o eixo x da mesma forma a quantidade percentual do elemento em análise B. Com este método é possível prever a característica da corrosão dentro de uma certa quantidade de concentração de ambos elementos. 


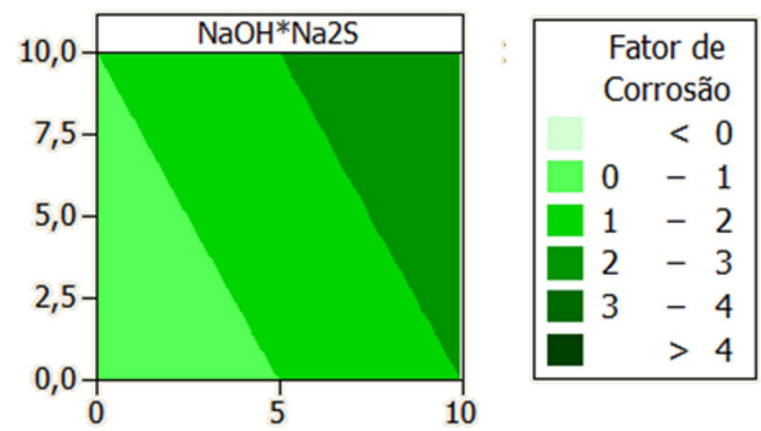

Figura 5. Análise do fator de corrosão pela interação $\mathrm{NaOH}$ com Na2S.
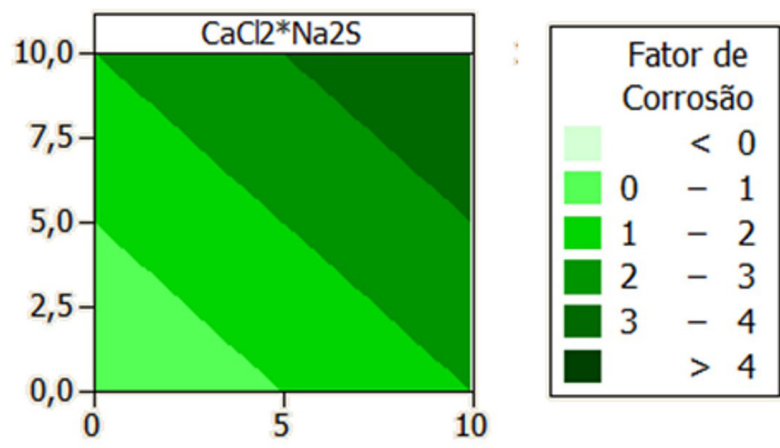

Figura 6. Análise do fator de corrosão pela interação $\mathrm{CaCl} 2$ com Na2S.
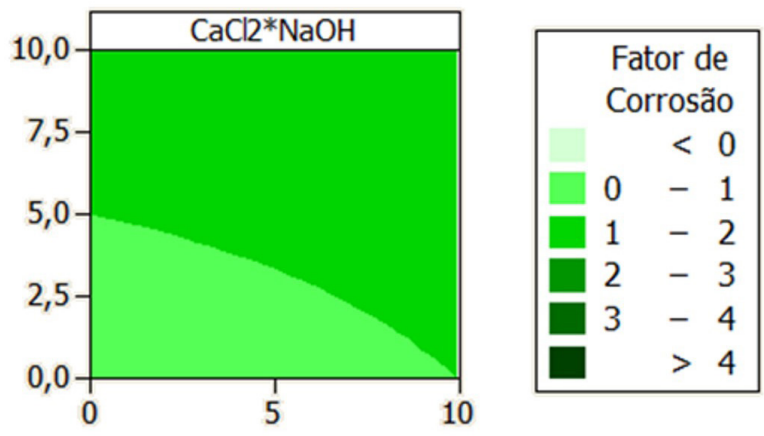

Figura 7. Análise do fator de corrosão pela interação $\mathrm{CaCl} 2 \mathrm{com} \mathrm{NaOH}$.
A Figura 5 apresenta as concentrações em y para o $\mathrm{NaOH}$ e em x para $\mathrm{Na}_{2} \mathrm{~S}$. Como explanado anteriormente, a presença de $\mathrm{NaOH}$ na solução com sulfeto de sódio apresenta um aumento no caráter corrosivo, o que pode ser estimado pela analise da Figura 5. Quando se atinge concentração máxima em estudo (10\%) de sulfeto de sódio o fator de corrosão encontrado é de 1 a 2 ; porém, quando na presença de qualquer quantidade de $\mathrm{NaOH}$ o fator passa de 2 a 3 , se mantendo até a concentração máxima de $\mathrm{NaOH}$ [22]. A presença de $\mathrm{NaOH}$ não afeta a corrosão de forma tão expressiva quanto o sulfeto, porém na concentração máxima em estudo seu efeito é similar à presença de sulfeto: na faixa de 5\% a 10\% de sulfeto, quando a concentração de hidróxido é máxima, o fator de corrosão permaneceu inalterado.

A Figura 6 apresenta a análise entre a interação do cloreto de cálcio e o sulfeto de sódio. Ela demonstra que ambas as soluções apresentam o mesmo potencial de corrosão. Quando na concentração máxima, ambos os compostos apresentam fator de corrosão 1 a 2; entretanto quando sobrepostos os efeitos dos compostos, aumenta o grau de oxidação para fatores de corrosão maior que 4 . Assim, o gráfico mostra que essas são as duas principais substâncias causadoras da corrosão nos sistemas impostos.

Na Figura 7 observa-se a análise do fator de corrosão em função da quantidade de cloreto de cálcio e Hidróxido de sódio presentes nas diferentes concentrações de eletrólito usadas no ensaio seletivo. $\mathrm{O} \mathrm{CaCl}$ apresentou durante os ensaios maior fator de corrosão em comparação ao $\mathrm{NaOH}$. Porém quando adicionado pequenas quantidades de cloreto na concentração máxima de $\mathrm{NaOH}$ o fator passa para 1 a 2, e quando em concentração superior a $5 \% \mathrm{de} \mathrm{CaCl}_{2}$ a corrosão atinge fator de corrosão $1 \mathrm{a} 2$, demonstrando o maior grau de oxidação.

A Figura 8 mostra a interação entre a bactéria inoculada e os demais fatores utilizados para causar corrosão no sistema.

A interação da bactéria, tanto com o sulfeto de sódio quanto com o cloreto de cálcio, apresentou similaridade, visto que ambos os compostos causam forte corrosão. A condição do gráfico demonstra que com qualquer concentração de bactéria a corrosão para o ensaio acelerado não é percebida [21].
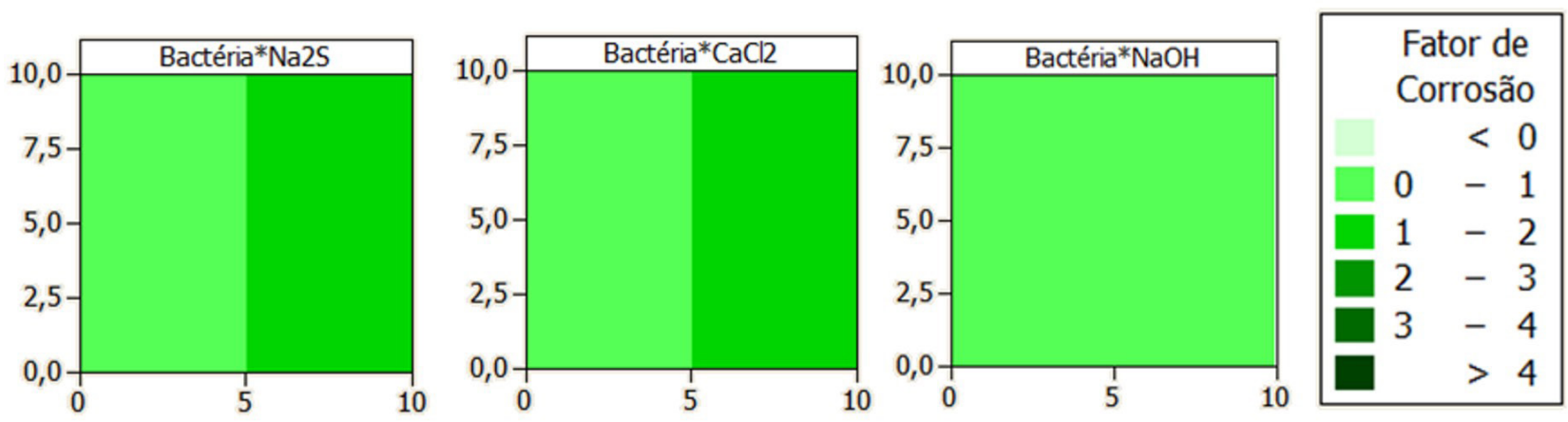

Figura 8. Análise da corrosão pela interação da Bactéria com os demais fatores. 


\section{Conclusões}

Os ensaios de corrosão por imersão mostraram que a corrosão gerada por biodiesel tem um caráter microbiológico, mas que para isso o tempo de exposição do metal ao composto deve ser suficiente para a formação de biofilme. As análises com ensaio acelerado adaptado para névoa salina obtiveram o resultado esperado, mostrando que a metodologia proposta parece ser promissora para a avaliação da corrosão do aço de tanques de armazenagem de biodiesel. Os ensaios acelerados seletivos mostraram que os íons sulfeto e cloreto são os principais agentes de corrosão no sistema avaliado. Contudo, a influência das bactérias no processo corrosivo durante os ensaios acelerados não pode ser evidenciada, pois o tempo de exposição na câmara não foi suficiente para a formação de biofilme. Assim, os ensaios acelerados adaptados serviram para demonstrar os agentes de corrosão físico-químicos preponderantes, mas não para evidenciar uma metodologia de avaliação adequada para a corrosão microbiológica, que provou-se, ocorre na presença de biodiesel.

\section{Agradecimentos}

Os autores deste trabalho agradecem à CAPES, CNPq, FAPERGS, Laboratório de Estudos Avançados em Materiais da Universidade Feevale.

\section{Referências}

1 Petrobras. N-270: Projeto de tanques de armazenagem atmosférico. Rio de Janeiro: Petrobras; 2010.

2 Lake LW, Arnold KE. Pretoleum engineering handbook: facilites and construction engineering. Richardson: Society of Petroleum Engineers; 1998. (Vol. 3).

3 Videla HA. Corrosão microbiológica. São Paulo: Blusher; 1993. 122 p.

4 Yeşilyurt MK, Öner IV, Yđlmaz EÇ. Biodiesel induced corrosion and degradation: a review. Pamukkale University Journal of Engineering Sciences. 2019;25(1):60-70. http://dx.doi.org/10.5505/pajes.2018.01885.

5 Ramadhani AN, Harimawan A, Devianto H. Water content effect on biofilm formation and bio-corrosion process in biodiesel-diesel storage tank. International Journal of Engineering \& Technology. 2018;7(4);2009-2012. http://dx.doi. org/10.14419/ijet.v7i4.15592.

6 Bento FM, Bücker F, Santestevan N, Cavalcanti EHS, Zimmer A, Gayçarde C et al. Impacto da adição do biodiesel ao óleo diesel durante a estocagem: um enfoque microbiológico e controle. Revista Biodiesel. 2010;47(14):1-5.

7 Loto CA. Microbiological corrosion: mechanism, control and impact: review. International Journal of Advanced Manufacturing Technology. 2017;92:4241-4252. http://dx.doi.org/10.1007/s00170-017-0494-8.

8 Lata S, Sharma C, Singh AK. Comparison of biocorrosion due to desulfovibrio desulfuricans and desulfotomaculum nigrificans bacteria. Journal of Materials Engineering and Performance. 2012;22(2):463-469. http://dx.doi. org/10.1007/s11665-012-0283-3.

9 Flemming, H.C. Introduction: Biofilms as a Particular Form of Microbial Life. In: Flemming, Hans-Curt; Geesey, Gill Gregory (ed.). Biofouling and Biocorrosion in Industrial Water Systems. Berlim: Springer-Verlag, 1991. Cap. 1. p. 1-6. Doi:10.1007/978-3-642-76543-8.

10 Albuquerque $\mathrm{AC}$, Andrade $\mathrm{C}, \mathrm{Neves} \mathrm{B}$. Biocorrosão: da integridade do biofilme à integridade do material. Corrosão e Protecção de Materiais. 2014 [acesso em 24 maio 2020];33(1-2):18-23. Disponível em: http://www.scielo.mec.pt/ scielo.php?script $=$ sci_arttext\&pid $=$ S0870-11642014000100003\&lng=pt\&nrm=iso

11. Agencia Nacional do Petroleo - ANP. Resolução ANP No 7. Brasília: ANP; 2008.

12 American Society for Testing and Materials - ASTM. G5-94: standard reference test method for making potentiostatic and potentiodynamic anodic polarization measurements. Philadelphia: ASTM; 2004.

13 American Society for Testing and Materials - ASTM. B117: standard practice for operating salt spray (fog) apparatus. Philadelphia: ASTM; 2019.

14 Gentil V. Corrosão. 6. ed. Rio de Janeiro: LTC; 2012. 360 p.

15 American Society for Testing and Materials - ASTM. G31-72: standard. practice for laboratory immersion corrosion testing of metals. Philadelphia: ASTM; 1999

16 Silva, LM; Llongueras, JG; Durán, R; Mendoza, J. Effect of flow on the corrosion mechanism of diferent api pipeline steels grades in nacl solutions containing CO2. New Orleans: NACE International; 2004

17 Sørensen PA, Kiil S, Dam-Johansen K, Weinell CE. Anticorrosive coatings: a review. Journal of Coatings Technology and Research. 2009;6(2):135-176. http://dx.doi.org/10.1007/s11998-008-9144-2. 
Klein et al.

18 Skerry BS, Alavi A, Lindgren KI. Environmental and electrochemical test methods for the evaluation of protective organic coatings. JCT. Journal of Coatings Technology. 1988;60(765):97-106.

19 Matos LAC. Estudo da corrosão de ligas ferrosas em diesel e biodiesel [dissertação]. Guarapuava: Universidade Estadual do Centro-Oeste; 2013.

20 Appleman BR. Survey of accelerated test methods for anti-corrosive coating performance. Journal of Coatings Technology. 1990;62(787):57-67.

21 Beech IB, Gaylarde CC. Recent advances in the study of biocorrosion: an overview. Revista de Microbiologia. 1999;30(3):117-190.

22 Alves SM, Dutra-Pereira FK, Bicudo TC. Influence of stainless steel corrosion on biodiesel oxidative stability during storage. Fuel. 2019;249:73-79.

Recebido em: 5 Nov. 2019

Aceito em: 3 Maio 2021 